\title{
The Impact of Late-Afternoon Stimulant Dosing for Children With ADHD on Parent and Parent-Child Domains
}

\author{
Andrea M. Chronis, William E. Pelham, Jr., Elizabeth M. Gnagy, John E. Roberts, \\ and Helen R. Aronoff \\ University at Buffalo, State University of New York
}

\begin{abstract}
Examined the impact of late-afternoon stimulant dosing on parent and parent-child domains. Twenty-one children with attention deficit hyperactivity disorder (ADHD) participated in a double-blind, placebo-controlled medication assessment comparing varying doses of methylphenidate (MPH) and Adderall in the context of an intensive treatment program. Children received varying doses of stimulant medication, including active medication or placebo at 3:30 p.m. daily. Parent ratings of their mood, pleasantness of parent-child interactions, and perceived parenting effectiveness and successfulness were obtained each evening. Effective medication doses had a beneficial impact on parent-child domains (e.g., parent-child interactions) but did not significantly affect non-child-related parent variables (e.g., negative affect [NA]). Findings suggested that doses with beneficial effects lasting into the evening improved parent reports of the pleasantness of parent-child interactions but were insufficient to produce positive changes in parent functioning.
\end{abstract}

Attention deficit hyperactivity disorder (ADHD) is a chronic disorder that is characterized by developmentally inappropriate levels of inattention, impulsivity, and hyperactivity (Diagnostic and Statistical Manual of Mental Disorders [4th ed. $\{D S M-I V\}$, American Psychiatric Association, 1994]). ADHD is associated with impairment in a number of important domains, including the parent-child relationship (Mash \& Johnston, 1982, 1983). Studies comparing the interactions between hyperactive children of various ages and their parents with normal parent-child dyads have consistently found clear differences in both child and parent behavior (for a review, see Danforth, Barkley, \& Stokes, 1991). Specifically, children with ADHD are less compliant, more oppositional, and less often able to follow parental requests through to completion (e.g., Cunningham \& Barkley, 1979; DuPaul, McGoey, Eckert, \& VanBrakle, 2001). In turn, parents of children with ADHD are more negative and reprimanding, issue more frequent commands, and are less responsive to their children's requests for attention than parents of normal children. Given the nature of these interactions, it is not surprising that parents of children with ADHD

This study was part of a project supported by a grant to William Pelham from Shire-Richwood Pharmaceuticals, Inc., manufacturer of Adderall. During this research and the preparation of this report, Pelham was also supported by grants from the National Institute on Alcohol Abuse and Alcoholism (AA11873) and the National Institute of Mental Health (MH50467 and MH53554).

Requests for reprints should be sent to Andrea Chronis, University of Maryland, Department of Psychology, Biology/Psychology Building, College Park, MD 20742.E-mail: achronis@psyc.umd.edu experience considerable stress, lower parenting selfesteem, and a higher prevalence of depression, marital problems, and divorce (see Fischer, 1990, \& Johnston \& Mash, 2001, for reviews).

It has been suggested that parental stress in these families may be better attributed to the presence of oppositional defiant disorder (ODD) and conduct disorder, both of which commonly co-occur with ADHD. However, the few studies that have directly examined the relative stress levels among parents of ADHD children with and without comorbid ODD or conduct disorder have been inconsistent in their findings. For example, Johnston (1996) found no differences in maternal psychological functioning among mothers of ADHD children with and without comorbid ODD but did find that mothers of oppositional children had lower self-esteem than parents of pure ADHD children. In contrast, Barkley, Anastopoulos, Guevremont, and Fletcher (1992) found that mothers of comorbid ADHD/ODD adolescents, but not pure ADHD adolescents, held more extreme negative beliefs about their parent-teen relationships and reported greater personal distress and less satisfaction in their marriages than mothers of controls. Thus, it is unclear to what extent oppositional behavior contributes to the stress parents of children with ADHD experience. Yet, parenting stress and self-esteem have consistently been shown to be related to the severity of children's behavior (e.g., Mash \& Johnston, 1982, 1983).

An extensive literature supports the efficacy of stimulant medication (i.e., methylphenidate [MPH] or Ritalin, dexadrine, pemoline) in reducing the negative 
behaviors associated with ADHD (see Swanson, McBurnett, Christian, \& Wigal, 1995). One would assume that, if stimulants reduce the negative behaviors that interfere with the social relationships of children with ADHD, their use would be associated with improvements in children's social functioning. Indeed, stimulants have been shown to have positive effects on teacher ratings of classroom behavior, parent-child interactions, and peer relationships (Swanson et al., 1995). In addition, studies have consistently shown that medicated children are more compliant with their parents' commands and better able to sustain attention for a longer period of time while executing these commands (Barkley, 1985; Barkley \& Cunningham, 1979, 1980) than unmedicated children. In response, mothers issue fewer commands and pay more attention to their children's positive behaviors and requests for attention when their children are medicated. Attending to positive child behavior is thought to increase the likelihood that the child will behave appropriately, thus creating more positive parent-child interactions. Despite these documented improvements in parent-child interactions, many children with ADHD are medicated only during school hours (i.e., in the morning and at lunchtime), often due to concerns about side effects (e.g., insomnia and appetite suppression).

To date, few studies have evaluated the relative effectiveness of a late-afternoon dose of MPH compared to standard twice-daily dosing (BID; Kent, Blader, Koplewicz, Abikoff, \& Foley, 1995; Stein et al., 1996). The first of these studies was a double-blind, crossover study of a 4:00 p.m. dose of either 10 or $15 \mathrm{mg}$ of MPH or placebo conducted on 12 child psychiatric inpatients with ADHD (Kent et al., 1995). Results of this study suggested that there was a beneficial effect of the third dose of medication on ratings of behavior by hospital staff and recorded behavior frequencies, with no adverse effects on sleep or appetite. However, generalizability of these findings to nonhospitalized, and presumably less severely impaired, children based on the reports of familiar adults in naturalistic settings is questionable.

The second of these studies addressed some of these limitations. Stein and colleagues (1996) conducted a triple-blind, placebo-controlled crossover study of MPH administered BID versus three times daily (TID) with 25 outpatients with ADHD. When BID and TID medication were directly compared, the TID regimen was associated with greater improvement on the Con- ners Parent Rating Scale Impulsivity/Hyperactivity factor (Conners, 1969). Although appetite suppression was rated as more severe on TID MPH, there were no differences in sleep duration on TID MPH relative to BID MPH. Of these studies, only Stein and colleagues addressed the impact of this dosing regimen on parent-child interactions. They found that parent-child conflicts as measured by the Child Conflict Index (Stein et al., 1996) were rated as improved on all medication regimens relative to placebo. When a direct comparison between the BID and TID conditions was made, there were fewer family conflicts on TID dosing; however, this difference was not significant (M. A. Stein, personal communication, December 18, 1998).

This study was part of a larger investigation that compared the time-course of MPH and Adderall to determine whether a single dose of Adderall administered in the morning had behavioral effects lasting throughout a typical school day (Pelham, Gnagy, et al., 1999). The rationale for this larger investigation was based on the findings of Swanson and colleagues (1998) and Pelham, Aronoff, and colleagues (1999), suggesting that Adderall has a longer course of action compared to MPH (i.e., higher doses of Adderall have effects lasting up to $6 \mathrm{hr}$, whereas MPH has behavioral effects lasting, on average, $4 \mathrm{hr}$ ) and is approximately twice as potent. In this investigation, varying doses of both MPH and Adderall (specifically, $0.3 \mathrm{mg} / \mathrm{kg}$ and $0.15 \mathrm{mg} / \mathrm{kg}$ ) administered at 3:30 p.m. were compared with placebo to evaluate the effectiveness of a late-afternoon medication dose and to determine whether a half-morning or (if applicable) lunchtime dose (i.e., $0.15 \mathrm{mg} / \mathrm{kg}$ as opposed to $0.3 \mathrm{mg} / \mathrm{kg}$ ) was sufficient in the late afternoon (see Table 1 for a description of the specific medication conditions). Results suggested that a single morning dose of Adderall produced positive behavioral effects that were equivalent to BID MPH and that lasted throughout a typical school day. On parent ratings of evening behavior, conditions in which a $0.3 \mathrm{mg} / \mathrm{kg}$ dose of MPH was administered at 3:30 p.m. produced behavioral improvements, whereas all three dosing regimens of Adderall (see Table 1) had significant beneficial effects on evening behavior, regardless of whether an active 3:30 p.m. dose was administered (Pelham, Gnagy, et al., 1999). Side effects, including appetite loss and difficulty sleeping, were more frequently reported when children received MPH 0.3 $\mathrm{mg} / \mathrm{kg}$ or either active dose of Adderall at 3:30 p.m. (Pelham, Gnagy, et al., 1999).

Table 1. Medication Conditions

\begin{tabular}{|c|c|c|c|c|c|c|c|}
\hline \multirow{2}{*}{$\frac{\text { Time }}{7: 30 \text { a.m. }}$} & \multirow{2}{*}{$\begin{array}{l}\text { Placebo } \\
\text { Placebo }\end{array}$} & \multicolumn{3}{|c|}{ Methylphenidate } & \multicolumn{3}{|c|}{ Adderall } \\
\hline & & $.3 \mathrm{mg} / \mathrm{kg}$ & $.3 \mathrm{mg} / \mathrm{kg}$ & $.3 \mathrm{mg} / \mathrm{kg}$ & $.3 \mathrm{mg} / \mathrm{kg}$ & $.3 \mathrm{mg} / \mathrm{kg}$ & $.3 \mathrm{mg} / \mathrm{kg}$ \\
\hline 11:30 a.m. & Placebo & $.3 \mathrm{mg} / \mathrm{kg}$ & $.3 \mathrm{mg} / \mathrm{kg}$ & Placebo & Placebo & Placebo & Placebo \\
\hline 3:30 p.m. & Placebo & $.3 \mathrm{mg} / \mathrm{kg}$ & $.15 \mathrm{mg} / \mathrm{kg}$ & Placebo & $.3 \mathrm{mg} / \mathrm{kg}$ & $.15 \mathrm{mg} / \mathrm{kg}$ & Placebo \\
\hline
\end{tabular}

Note: $\mathrm{Mg} / \mathrm{kg}$ refers to $\mathrm{mg}$ of stimulant medication per $\mathrm{kg}$ of body weight. 
The purpose of this study was to examine the impact of these varying doses of stimulant medication, particularly 3:30 p.m. doses, on parent self-reports of their mood, pleasantness of parent-child interactions, and perceived parenting competency. It was predicted that medication doses that had beneficial effects on parent reports of child evening behavior (Pelham, Gnagy, et al., 1999) would also result in corresponding improvements in parent domains (positive affect [PA], negative affect [NA], ability to complete tasks) and parent-child domains (pleasantness of interactions, parents' ability to get children to complete their tasks, and parents' perceptions of their effectiveness in the parenting role).

\section{Method}

\section{Participants}

Twenty-one children participated in this study. All children were enrolled in the 1998 Summer Treatment Program (STP) at the State University of New York at Buffalo. Prior to the 1st week of the treatment program, the option to participate in this medication assessment was presented to the parents of the 48 children who were enrolled in the program. The procedures for the medication assessment were described in detail to these parents, and it was explained that they would be provided with individualized medication recommendations for their children following the assessment. In addition, the parents were told that we were interested in studying the impact of evening medication on the parents' own mood and feelings of competence. Of these 48 children, 21 parents elected to participate (parents of 19 boys and 2 girls). Informed consent was obtained from parents, and all children provided their assent.

Chi-square (for categorical variables) and $t$ tests (for continuous variables) were conducted to compare the 21 children whose parents elected to participate and the 27 children who declined participation on a number of variables, including child age, IQ and achievement scores, medication status at the beginning of the STP, parent and teacher IOWA Conners scores at STP intake, and parents' marital status, educational attainment, and income. The only variable that differed significantly between participants and nonparticipants was participation in the prior STP, $\chi^{2}(1)=6.97, p=$ .008 . This was presumably because most of these children participated in a trial of MPH and Adderall the prior year (see Pelham, Aronoff, et al., 1999), in which individualized recommendations were made for which drug was more effective. Thus, these families had little motivation to participate in another medication assessment comparing these drugs.

A semistructured disruptive behavior disorder (DBD) parent interview consisting of the DSM-IV symptoms with situational probes was conducted by clinical psychology graduate students. In addition, par- ents and teachers completed the DBD rating scale (Loney \& Milich, 1982; Pelham, Evans, Gnagy, \& Greenslade, 1992; Pelham, Milich, Murphy, \& Murphy, 1989). When discrepancies existed between parent responses on the DBD interview and on the DBD rating scale, parents were queried as to which response was more accurate. Symptoms were considered present if they were endorsed by either the parent during the semistructured interview or teacher on the DBD rating scale, with at least one ADHD symptom being endorsed at both home and school for the diagnosis to be made $(D S M-I V)$. Based on these assessment procedures, all children met $D S M-I V$ criteria for ADHD (any subtype) prior to their participation in the STP. In addition, 14 of the participants were classified as having comorbid ODD and another 5 as having comorbid conduct disorder. They ranged in age from 6 to 12 years $(M=10.26)$ at the time of study and had no medical history that prohibited them from taking stimulant medication or participating in the STP academic or recreational activities. The participants' mean IQ was $109.9(S D=18.8)$. Sixteen of these children received stimulant medication prior to beginning the STP (14 received MPH, 1 received Dexadrine, and 1 received Concerta MPH). The median yearly family income for these participants was $\$ 35,000$, with incomes ranging widely (under $\$ 15,000$ per year to over $\$ 100,000$ per year). Participant characteristics are described in Table 2.

\section{Procedure}

The STP is an intensive, 8-week behavioral treatment program that combines sports-skills training, social-skills training, and problem-solving skills training

Table 2. Means and Standard Deviations for Participant Characteristics

\begin{tabular}{lrr}
\hline Item & $\boldsymbol{M}$ & $\boldsymbol{S D}$ \\
\hline Race (\% White) & 100 & \\
Child age in years & 10.3 & 1.9 \\
Parents' marital status (\% married) $^{\text {Intelligence quotient }}{ }^{\mathrm{a}}$ & 66.7 & \\
Reading achievement $^{\mathrm{a}}$ & 109.9 & 18.8 \\
Math achievement $^{\mathrm{a}}$ & 91.2 & 26.6 \\
ADHD inattention interview items endorsed & 103.2 & 18.0 \\
ADHD hyperactivity interview items endorsed & 6.1 & 3.0 \\
Oppositional/defiant interview items endorsed & 5.5 & 3.0 \\
Conduct disorder interview items endorsed & 4.3 & 3.4 \\
Abbreviated Conners Rating Scale Parent & 0.9 & 1.3 \\
Abbreviated Conners Rating Scale Teacher & 13.1 & 4.9 \\
IOWA Conners Teacher Rating Scale & 11.0 & 5.7 \\
$\quad$ Inattention-Overactivity & & \\
Oppositional-Defiant & 2.2 & 2.0 \\
\hline
\end{tabular}

${ }^{a}$ When children had not received recent IQ or achievement testing at school, the vocabulary and block design subtests of the Wechsler Intelligence Scale for Children-Third Edition (Weschler, 1991) were administered to provide an estimated full-scale IQ, and the Wechsler Individual Achievement Test-Screener (Weschler, 1992) was administered to assess reading and math achievement. 
in the context of a point system (Pelham \& Hoza, 1996). A daily report card (DRC) on which specific problem behaviors are targeted is shared with parents at the end of each treatment day, and parents are taught to provide rewards at home for attainment of each behavioral goal. Parents also attend weekly behavioral parent training classes utilizing a combination of Cunningham's Community Parenting Education program (Cunningham, Bremner, \& Secord-Gilbert, 1994) and the Parent Training Manual employed in the Multimodal Treatment Study for ADHD (MTA) study (Abikoff et al., 1994). Some topics (e.g., commands) were presented didactically, in the manner outlined by Abikoff and colleagues. Topics covered in parent training classes included praising prosocial behaviors, ignoring mildly inappropriate behaviors, giving effective commands, implementing time-out for serious negative behavior, and designing a home point/token system. Thus, the scope of the STP is intended to extend beyond the treatment day and into the home via the DRC and the parent training program.

Beginning in Week 3 of the program, children participated in a double-blind, placebo-controlled medication assessment in which the seven medication conditions depicted in Table 1 were randomized by day (Pelham, Gnagy, et al., 1999). All participants received medication each Monday through Thursday over a period of 6 weeks for a 24-day clinical medication assessment. Active medication and placebo were disguised in opaque gelatin capsules by a local pharmacy and were dispensed in daily pill reminders by the study doctor (Helen R. Aronoff). Within each 8-day segment of the assessment period, placebo occurred twice and each other condition occurred once, with the order of the conditions randomized on a daily basis for each individual child. Thus, it was intended that each child would have approximately 3 days of data in each of the active drug conditions and 6 days in the placebo condition, with absences accounting for reductions from the planned number of days per condition. A detailed description of our medication assessment procedure is presented elsewhere (e.g., Pelham, 1993).

Families were asked to designate the person who interacted most with the child on the majority of weeknights to complete daily child behavioral and side-effects ratings and self-report ratings of mood and perceived efficacy. Primary raters included mothers $(n$ $=17)$, fathers $(n=2)$, and others $(n=2$, a nanny and a step-parent, both of whom were primary caregivers for the child). On a few evenings, for a variety of reasons, a person other than the primary rater completed the ratings; however, following such occasions, the first author emphasized to the family the importance of consistently having the same person complete the ratings. To ensure that ratings were completed each evening rather than retrospectively, parents were instructed either to fax their ratings or to record their responses in a voice mailbox on completion. If parents had not sent responses within 20 min after their child's usual bedtime (ranging from 8:00 p.m. until 10:00 p.m.), the first author immediately called and prompted them to complete the ratings. Parents often gave their responses during this reminder phone call. Using these data collection procedures, $100 \%$ of possible data were obtained for evening parent ratings. Ninety-two percent of these ratings were completed by primary raters.

\section{Measures}

Parent affect. The Positive and Negative Affect Schedule (PANAS; Watson, Clark, \& Tellegen, 1988) is a brief, easy-to-administer mood scale, which consists of two 10-item subscales representing the dimensions of positive affect (PA) and negative affect (NA; Watson et al., 1988). PA reflects the extent to which an individual feels active and engaged, with high PA indicating a greater degree of activity and low PA reflecting lethargy. PA items include interested, alert, excited, inspired, strong, determined, attentive, enthusiastic, active, and proud. NA reflects the degree to which the individual is experiencing a variety of negative mood states. NA items include irritable, distressed, ashamed, upset, nervous, guilty, scared, hostile, jittery, and afraid. Parents were asked to rate the degree to which each item on the PANAS reflected their mood that evening using a 5-point scale ranging from 1 (very slightly or not at all) to 5 (extremely). Scores on the PA and NA subscales can range from 10 to 50. In this sample, PA scores ranged from 10 to 49, and NA scores ranged from 10 to 40.

The PANAS was developed and validated as a measure of fluctuations in mood (Watson et al., 1988) and is widely employed for that purpose in diverse populations (e.g., Randall \& Cox, 2001). The PANAS PA and NA scales have been shown to be highly internally consistent, with coefficient alphas ranging from 0.86 to 0.90 for PA and from 0.84 to 0.87 for NA (Watson et al., 1988). Correlations between the PA and NA scales have been shown to be very low, ranging from -0.12 to -0.23 (Watson et al., 1988). Over an 8-week retest interval, test-retest reliability coefficients of the PANAS with different time frames rated (e.g., past day, past week) ranged from 0.47 to 0.68 for the PA scale and from 0.39 to 0.71 for the NA scale (Watson et al., 1988). Thus, the PANAS showed a significant level of stability in every time frame; however, test-retest reliability was shown to increase as the time frame lengthened. In this sample, coefficient alphas for the PA and NA scales, respectively, were 0.92 and 0.88 , and ranged from 0.85 to 0.94 for PA and from 0.58 to 0.95 for NA when alphas were computed separately for each medication condition. No pattern was observed by which the magnitude of alpha coefficients appeared to be related to medication condition. Also in this sample, PA and NA were correlated -0.22 . 
Pleasantness, successfulness, and effectiveness ratings. Parents also completed a series of questions referring to the pleasantness of interacting with the child, success of the parent in completing his or her own tasks, success of the parent in getting the child to complete his or her own tasks, and overall effectiveness in the parenting role (Pelham et al., 1997, 1998, 2000). Ratings of pleasantness, success, and overall effectiveness were made on a 7-point Likert scale, ranging from 0 (very pleasant/successful/effective) to 6 (very unpleasant/unsuccessful/ineffective). These questions have been shown to discriminate between parental interactions with normal and deviant children (Pelham et al., 1997, 1998, 2000).

Coefficient alphas were computed to examine the intercorrelations between these parent-child interaction items. The coefficient alpha was 0.86 in this sample, ranging from 0.76 to 0.91 when alphas were computed separately for each medication condition. Again, no pattern was observed by which the magnitude of alpha coefficients appeared to be related to medication condition.

\section{Results}

\section{Analytic Strategy}

To evaluate the effects of child medication on parent functioning, repeated-measures multivariate analyses of variance were conducted comparing the aggregate of all medication conditions to the placebo condition on all parent and parent-child measures to determine whether there was an overall effect of medication (see Pelham, Gnagy, et al., 1999). Each significant multivariate analysis of variance was then followed by specific planned contrasts (BMDP 4V) between each child's within-participant mean for each of the seven medication conditions and placebo to determine the specific nature of the effect. For each parent measure, effect sizes $(d)$ were computed by subtracting the group mean for each drug condition from the group placebo mean and then dividing by the standard deviation for the placebo condition. All analyses were originally completed including each day of the medication assessment, regardless of who completed the ratings. To rule out the possibility that the $8 \%$ of ratings completed by a nonprimary rater influenced the results, analyses were repeated excluding nonprimary rater questionnaires. No differences were found between these two methods; thus, data from all raters are included in the remainder of the analyses to maximize the available data.

\section{Effects of Medication on Parent Affect and Perceived Competence}

Comparisons between the placebo condition and the aggregate of all active medication conditions re- vealed no significant effect of medication on PA, $F(1$, $20)=2.30, p=.14$; NA, $F(1,20)=2.61, p=.12$; or success of the parent in completing his or her own activities, $F(1,20)=1.00, p=.32$. However, significant effects of medication were found for the pleasantness of parent-child interactions, $F(1,20)=18.58, p<.001$; parent's success in having the child complete his or her activities, $F(1,20)=5.74, p<.05$; and parents' overall effectiveness in the parenting role, $F(1,20)=8.87, p<$ .01 . Table 3 presents means, standard deviations, and effect sizes.

The results of follow-up planned contrasts are presented in Table 3. Because of the large number of contrasts, we report only those significant at $p<.01$. Both MPH $0.3 \mathrm{mg} / \mathrm{kg}$ TID and Adderall $0.3 \mathrm{mg} / \mathrm{kg}$ in the morning and $0.15 \mathrm{mg} / \mathrm{kg}$ in the late afternoon were significantly different from placebo on parent ratings of their ability to get children to complete tasks, overall effectiveness in the parenting role, and pleasantness of parent-child interactions. Adderall $0.3 \mathrm{mg} / \mathrm{kg}$ in the morning and at 3:30 p.m., Adderall $0.3 \mathrm{mg} / \mathrm{kg}$ in the morning only and MPH $0.3 \mathrm{mg} / \mathrm{kg}$ in the morning only were also significantly different from placebo with regard to the pleasantness of parent-child interactions. However, the largest effect sizes with regard to pleasantness were most often found with doses that had the greatest effects on behavior, that is, MPH $0.3 \mathrm{mg} / \mathrm{kg}$ TID and all three Adderall conditions (Pelham, Gnagy, et al., 1999).

\section{Discussion}

This study extends the findings of Kent et al. (1995), Stein et al. (1996), and Pelham, Gnagy, et al. (1999), who suggested that a late-afternoon dose of stimulant medication has beneficial effects on child behavior by examining the impact of this additional dose on parent functioning. Based on previous studies that reported improved parent-child interactions when children with ADHD were medicated (e.g., Barkley, 1985), it was hypothesized that effective late-afternoon stimulant doses would improve parents' mood and perceived success and effectiveness in the parenting role. In fact, results suggested that medication-dosing regimens that we have previously documented as having beneficial behavioral effects lasting into the evening hours (Pelham, Gnagy, et al., 1999) were associated with improvements in parent-child domains-the pleasantness of parent-child interactions, parents' success in having their children complete tasks, and parents' overall feelings of effectiveness in the parenting role-but not in non-child-related parental domainsparental mood and task completion.

Significant effects of drug condition and moderate to large effect sizes were found for most parent-child domains: pleasantness of parent-child interactions, 


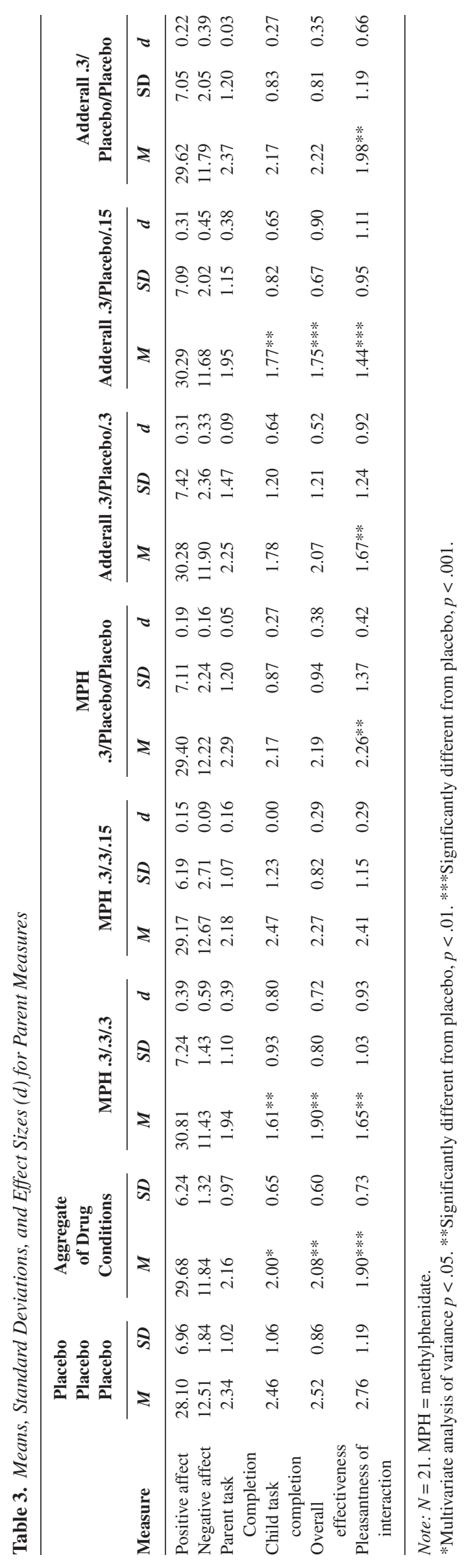


parents' success in having their children complete tasks, and parents' overall feelings of parenting effectiveness. The largest effects on these items were consistently found when the children received $\mathrm{MPH}$ $0.3 \mathrm{mg} / \mathrm{kg}$ TID or Adderall $0.15 \mathrm{mg} / \mathrm{kg}$ or $0.3 \mathrm{mg} / \mathrm{kg}$ at 3:30 p.m., which is consistent with medication effects on child behavior reported by Pelham, Gnagy, et al. (1999). On some measures (i.e., NA) for which statistical significance was not reached, Adderall $0.3 \mathrm{mg} / \mathrm{kg}$ administered once in the morning produced small to medium effects as well. These findings are not surprising given the drug effects on child behavior that we previously reported in this study (Pelham, Gnagy, et al., 1999). For example, when children with ADHD are more attentive and less oppositional, we would expect their parents to feel more successful in obtaining their cooperation in completing tasks.

More surprising was the fact that MPH administered only once in the morning showed small to moderate effects on the pleasantness of parent-child interactions, particularly because this dose did not have significant beneficial effects on evening child behavior. These findings are somewhat consistent with those of Stein and colleagues (1996), who reported a reduction in parent-child conflicts on both BID and TID medication regimens relative to placebo but no significant differences between the BID and TID conditions despite improved evening behavior on TID medication. Carry-over from the treatment day may have contributed to this effect. For instance, parents were given feedback regarding their children's DRC performance at the end of each treatment day and were instructed to reward their children at home for success on the DRC. Even a once-administered dose of MPH improved the likelihood that the child would receive a positive DRC (Pelham, Gnagy, et al., 1999). The possibility exists that this positive feedback impacted parents' response to their children and "set them on the right foot" for their interactions that evening. Yet, it remains unclear why this same effect was not found for MPH .3/.3/.15, which also failed to result in significant behavioral effects, but did not show the same carry-over effect on parent-child interaction measures.

It is also unclear why Adderall $0.15 \mathrm{mg} / \mathrm{kg}$ at $3: 30$ was more consistently associated with larger effect sizes and significant differences from placebo than was Adderall $0.3 \mathrm{mg} / \mathrm{kg}$, particularly because no significant differences were found between the two doses with regard to behavioral effects, side effects, or parent-child interaction measures. Although there were no significant differences in side effects between these two lateafternoon doses of Adderall in the sample overall, on close examination it appeared that in a few cases, parents indicated that their children were at least moderately "dull" on Adderall $0.3 \mathrm{mg} / \mathrm{kg}$ but not on 0.15 $\mathrm{mg} / \mathrm{kg}$. Likewise, when individual children were examined, MPH .3/.3/.15 was associated with crabbiness and skin picking on a few days, whereas the other MPH doses were not. It is entirely possible that such slight individual differences in side effects may have contributed to these inconsistent findings. This highlights the need to evaluate not only potential benefits of medication but also the side effects associated with these dosing regimens when making treatment recommendations.

Although we demonstrated that a late-afternoon dose of medication had a beneficial impact on child behavior and it is likely that child behavior contributes to parent mood and stress, medication doses with beneficial effects lasting into the evening hours did not influence non-child-related parent variables. In addition to the treatment-related factors described later, events that occurred during the course of the parents' days likely contributed to their mood in the evening. The instructions on the mood questionnaires asked parents to reflect on their general feelings that evening. Thus, a number of variables aside from their children's evening behavior (e.g., occupational problems, marital conflict) could have affected parents' mood on any given evening. We expected that effects would have been clear had we asked only about parents' mood as related to their children. Additionally, it is possible that parent characteristics (e.g., anxiety) contributed to their responses to child behavior above and beyond the effects of child medication. Unfortunately, information related to parent personality was not obtained and therefore could not be examined.

The fact that this study was conducted in the context of an intensive treatment program may have affected its results. The STP treatment day begins at 8:00 a.m. and ends at 5:00 p.m., leaving parents without the stress of managing their children's behavior and free to complete their own chores and errands throughout the day. In fact, on average, parents in this study rated themselves as having very little NA overall. Aside from the direct psychosocial and pharmacological intervention with these children, there is some evidence to suggest that the parent training component of the STP may have also impacted parent stress and self-esteem (Anastopoulos, Shelton, DuPaul, \& Guevremont, 1993). Measures of perceived effectiveness and mood were not obtained prior to the program; thus, we do not have a baseline by which we can compare parents' ratings during the medication evaluation.

Parents also completed these questionnaires daily, and it is possible that repeated administration of measures had an impact on their responses. Studies have suggested that repeated administrations of the Beck Depression Inventory and other negative mood measures (Ahava, Iannone, Grebstein, \& Schirling, 1998; Sharpe \& Gilbert, 1998) and the IOWA Conners (Pelham \& Smith, 2000) result in steady declines. On examination of PANAS scores, this was not the case in this study; however, this phenomenon likely contributed to the low parent IOWA Conners scores. 
Finally, participants were primarily Caucasian, middle- to upper-middle-class families involved in a university-based treatment program. It is unclear whether the results of this study may be generalized to individuals from minority groups or disadvantaged backgrounds. Hypothesized differences in children's response to stimulant medication due to socioeconomic variables have largely been attributed to differences in attendance or compliance (Rieppi et al., 2002). Some studies have suggested that less educated families, those from lower socioeconomic groups, and children who are more impaired or less intelligent may be less adherent to medication regimens (Brown, Borden, \& Clingerman, 1985; Brown, Borden, Wynne, Spunt, \& Clingerman, 1987; Firestone, 1982). The nature of the STP requires that families be highly compliant with the demands of the program. This likely limits the generalizability of our findings to families who are capable of complying with an intensive treatment program. Yet, at the same time, our sample was quite severe-more than $90 \%$ of the children were diagnosed with a comorbid ODD (66\%) or conduct disorder (24\%). These comorbidity rates, particularly for ODD, are higher than Barkley's (1990) reports that $35 \%$ to $60 \%$ of children with ADHD will meet criteria for ODD by age 7 or later. This was likely a result of selection - that is, parents who enrolled their children in this intensive, time-consuming, and costly treatment program likely did so because their children were severely impaired. It is recommended that future studies attempt to address these same research questions in more disadvantaged populations and those who are not enrolled in an intensive treatment program. Future studies may also attempt to include more children with pure ADHD as well as children with comorbid ODD or conduct disorder, so that efforts can be made to better understand the role that comorbidity plays in negative parent-child interactions.

Overall, results of this study suggest that child medication regimens that have beneficial effects on evening child behavior may also positively impact parent-child domains, such as the pleasantness of interactions, ability of parents to get children to complete tasks, and parents' perceived parenting efficacy. In contrast, stimulant medication administered to children was not enough to improve parents' affect or ability to complete their own tasks. This suggests that other interventions (e.g., psychosocial interventions) may be warranted for parents who are particularly vulnerable to their children's negative behavior. Preliminary results of a study evaluating the effectiveness of cognitive-behavioral therapy for mothers of children with ADHD indicate that this may be a promising intervention for even mildly distressed participants (Chronis, Roberts, Pelham, \& Gamble, 2001).

Further examination of the question of whether late-afternoon doses of stimulant medication and new long-acting stimulant preparations designed to last up to $12 \mathrm{hr}$ (e.g., Concerta, Metadate, Adderall-XR) have beneficial effects on parent-child interactions and parent functioning (e.g., their mood and perceptions of parenting efficacy and success) is suggested. These studies should include larger, culturally and economically diverse samples and should be conducted outside of a comprehensive treatment program. Measures of stress specific to parenting may be included, as these measures will likely be more sensitive to the effects of child behavior. Evaluations of past and current parental psychopathology using structured clinical interviews are suggested to determine which parental characteristics predict greater reactivity to child misbehavior. Such evaluations will be particularly useful to professionals providing services to these families, so that they may address any parental problems that may present obstacles to the child's treatment.

\section{References}

Abikoff, H., Abramowitz, A., Courtney, M., Cousins, L., Del Carmen, R., Eddy, M., et al. (1994). Parent training manual: MTA study. Unpublished manuscript.

Ahava, G. W., Iannone, C., Grebstein, L., \& Schirling, J. (1998). Is the Beck Depression Inventory reliable over time? An evaluation of multiple test-retest reliability in a nonclinical college student sample. Journal of Personality Assessment, 70, 222-231.

American Psychiatric Association. (1994). Diagnostic and statistical manual of mental disorders (4th ed.). Washington, DC: Author.

Anastopoulos, A. D., Shelton, T. L., DuPaul, G. J., \& Guevremont, D. C. (1993). Parent training for attention-deficit hyperactivity disorder: Its impact on parent functioning. Journal of Abnormal Child Psychology, 21, 581-596.

Barkley, R. A. (1985). The effects of methylphenidate on the interactions of preschool ADHD children with their mothers. Journal of the American Academy of Child and Adolescent Psychiatry, 27, 336-341.

Barkley, R. A. (1990). Attention-deficit hyperactivity disorder: A handbook for diagnosis and treatment. New York: Guilford.

Barkley, R. A., Anastopoulos, A. D., Guevremont, D. C., \& Fletcher, K. E. (1992). Adolescents with attention deficit hyperactivity disorder: Mother-adolescent interactions, family beliefs and conflicts, and maternal psychopathology. Journal of Abnormal Child Psychology, 20, 263-288.

Barkley, R. A., \& Cunningham, C. E. (1979). The effects of methylphenidate on the mother-child interactions of hyperactive children. Archives of General Psychiatry, 36, 201-208.

Barkley, R. A., \& Cunningham, C. E. (1980). The parent-child interactions of hyperactive children and their modification with stimulant drugs. In R. Knights \& D. Bakker (Eds.), Treatment of hyperactive and learning disordered children (pp. 219-236). Baltimore, MD: University Park Press.

Brown, R. T., Borden, K. A., \& Clingerman, S. R. (1985). Adherence to methylphenidate therapy in a pediatric population: A preliminary investigation. Psychopharmacology Bulletin, 21, 28-36.

Brown, R. T., Borden, K. A., Wynne, M. E., Spunt, A. L., \& Clingerman, S. R. (1987). Compliance with pharmacological and cognitive treatments for attention deficit disorder. Journal of the American Academy of Child and Adolescent Psychiatry, 26, 521-526. 
Chronis, A. M., Roberts, J. E., Pelham, W. E., \& Gamble, S. A. (2001, November). The addition of "The Coping With Depression Course" to behavioral parent training for mothers of children with ADHD. Poster presented at the meeting of the Association for the Advancement of Behavior Therapy, Philadelphia, PA.

Conners, C. K. (1969). A teacher rating scale for use in drug studies with children. American Journal of Psychiatry, 126, 152-156.

Cunningham, C. E., \& Barkley, R. A. (1979). The interactions of normal and hyperactive children with their mothers in free play and structured tasks. Child Development, 50, 217-224.

Cunningham, C. E., Bremner, R., \& Secord-Gilbert, M. (1994). The Community Parent Education (COPE) program: A school based family systems oriented course for parents of children with disruptive behavior disorders. Unpublished manuscript.

Danforth, J. S., Barkley, R. A., \& Stokes, T. F. (1991). Observations of parent-child interactions with hyperactive children: Research and clinical implications. Clinical Psychology Review, 11, 703-727.

DuPaul, G. J., McGoey, K. E., Eckert, T. L., \& VanBrakle, J. (2001). Preschool children with attention-deficit/hyperactivity disorder: Impairments in behavioral, social, and school functioning. Journal of the American Academy of Child and Adolescent Psychiatry, 40, 508-515.

Firestone, P. (1982). Factors associated with children's adherence to stimulant medication. American Journal of Orthopsychiatry, 52, 447-457.

Fischer, M. (1990). Parenting stress and the child with attention deficit hyperactivity disorder. Journal of Clinical Child Psychology, 19, 337-346.

Johnston, C. (1996). Parent characteristics and parent-child interactions in families of nonproblem children and ADHD children with higher and lower levels of oppositional-defiant behavior. Journal of Abnormal Child Psychology, 24, 85-104.

Johnston, C., \& Mash, E. J. (2001). Families of children with attention deficit hyperactivity disorder: Review and recommendations for future research. Clinical Child and Family Psychology Review, 4, 183-207.

Kent, J. D., Blader, J. C., Koplewicz, H. S., Abikoff, H., \& Foley, C. A. (1995). Effects of late-afternoon methylphenidate administration on behavior and sleep in attention-deficit hyperactivity disorder. Pediatrics, 96, 320-325.

Loney, J., \& Milich, R. (1982). Hyperactivity, inattention, and aggression in clinical practice. In M. Wolraich \& D. K. Routh (Eds.), Advances in developmental and behavioral pediatrics (pp. 113-147). Greenwich, CN: JAI.

Mash, E. J., \& Johnston, C. (1982). A comparison of the mother-child interactions of younger and older hyperactive and normal children. Child Development, 53, 1371-1381.

Mash, E. J., \& Johnston, C. (1983). Parental perceptions of child behavior problems, parenting self-esteem, and mothers' reported stress in younger and older hyperactive and normal children. Journal of Consulting and Clinical Psychology, 51, 86-99.

Pelham, W. E. (1993). Pharmacotherapy for children with attention-deficit hyperactivity disorder. School Psychology Review, 22, 199-227.

Pelham, W. E., Aronoff, H. R., Midlam, J. K., Shapiro, C. J., Gnagy, E. M., Chronis, A. M., et al. (1999). A comparison of Ritalin and Adderall: Efficacy and time-course in children with attention-deficit/ hyperactivity disorder. Pediatrics, 103, 43.

Pelham, W. E., Evans, S. W., Gnagy, E. M., \& Greenslade, K. E. (1992). Teacher ratings of $D S M-I I I-R$ symptoms for the disruptive behavior disorders: Prevalence, factor analyses, and conditional probabilities in a special education sample. School Psychology Review, 21, 285-299.
Pelham, W. E., Gnagy, E. M., Chronis, A. M., Burrows-MacLean, L., Fabiano, G. A., Onyango, A. N., et al. (1999). A comparison of q.A.M., b.i.d., and t.i.d. methylphenidate and q.A.M. and b.i.d. Adderall in children with ADHD. Pediatrics, 104, 1300-1311.

Pelham, W. E., \& Hoza, B. (1996). Intensive treatment: A summer treatment program for children with ADHD. In E. Hibbs \& P. Jensen (Eds.), Psychosocial treatments for child and adolescent disorders: Empirically based strategies for clinical practice (pp. 311-340). New York: APA Press.

Pelham, W.E., Lang, A. R., Atkeson, B., Murphy, D. A., Gnagy, E. M., Greiner, A. R., et al. (1997). Effects of deviant child behavior on parental distress and alcohol consumption in laboratory interactions. Journal of Abnormal Child Psychology, 25, 413-424.

Pelham, W. E., Lang, A. R., Atkeson, B., Murphy, D. A., Gnagy, E. M., Greiner, A. R., et al. (1998). Effects of deviant child behavior on parental alcohol consumption: Stress-induced drinking in parents of ADHD children. The American Journal on Addictions, 7, 103-114.

Pelham, W. E., Lang, A. R., Jacob, R. G., Blumenthal, J. D., Baumann, B. L., \& Meisinger, K. D. (2000). A laboratory study of the effects of deviant child behavior on subjective and physiological distress and alcohol consumption in mothers with positive and negative family histories of alcoholism. Manuscript submitted for publication.

Pelham, W. E., Milich, R., Murphy, D. A., \& Murphy, H. A. (1989). Normative data on the IOWA Conners Teacher Rating Scale. Journal of Clinical Child Psychology, 18, 259-262.

Pelham, W. E., \& Smith, B. H. (2000). Prediction and measurement of individual responses to Ritalin by children and adolescents with ADHD. In L. Greenhill \& B. P. Osman (Eds.), Ritalin: Theory and practice (pp.193-218). New York: Mary Ann Liebert.

Randall, D. M., \& Cox, W. M. (2001). Experimental mood inductions in persons at high and low risk for alcohol problems. American Journal of Drug and Alcohol Abuse, 27, 183-187.

Rieppi, R., Greenhill, L. L., Ford, R. E., Chuang, S., Wu, M., Davies, M., et al. (2002). Socioeconomic status as a moderator of ADHD treatment outcomes. Journal of the American Academy of Child and Adolescent Psychiatry, 41, 269-277.

Sharpe, J. P., \& Gilbert, D. G. (1998). Effects of repeated administration of the Beck Depression Inventory and other measures of negative mood states. Personality and Individual Differences, 24, 457-463.

Stein, M. A., Blondis, T. A., Schnitzler, E. R., O'Brien, T., Fishkin, J., Blackwell, B., et al. (1996). Methylphenidate dosing: Twice versus three times daily. Pediatrics, 98, 748-756.

Swanson, J. M., McBurnett, K., Christian, D. L., \& Wigal, T. (1995). Stimulant medications and the treatment of children with ADHD. Advances in Clinical Child Psychology, 17, 265-322.

Swanson, J., Wigal, S., Greenhill, L., Brown, R., Waslick, B., Lerner, M., et al. (1998). Objective and subjective measures of the pharmacodynamic effects of Adderall in the treatment of children with ADHD in a controlled laboratory classroom setting. Psychopharmacology Bulletin, 34, 55-60.

Watson, D., Clark, L. A., \& Tellegen, A. (1988). Development and validation of brief measures of positive and negative affect: The PANAS scales. Journal of Personality and Social Psychology, 54, 1063-1070.

Wechsler, D. (1991). Wechsler Intelligence Scale for Children-third edition: Manual. San Antonio: Psychological Corporation.

Wechsler, D. (1992). Wechsler Individual Achievement Test: Manual. San Antonio: Psychological Corporation.

Received January 16, 2002

Accepted October 1, 2002 